\title{
LAS DIFERENTES MIRADAS A LA NOCIÓN DE CULTURA Y LOS EFECTOS DE LA GLOBALIZACIÓN CULTURAL
}

\author{
Carmen Martínez Samper \\ Universidad de Zaragoza (C. Teruel). Dpto Expresión Musical, Plástica y Corporal
}

\section{Resumen}

El concepto "cultura" ha evolucionado a lo largo de varios siglos, así como su relación con la sociedad. Desde sus orígenes, en los primeros análisis desarrollados por las ciencias sociales (s. XIX), se hizo necesaria una reflexión e interpretación precisa del uso de este concepto dentro de los distintos ámbitos que generan conocimiento. Nuevos códigos, culturas alternativas, nuevos límites y aperturas enriquecen el panorama artístico pero, a su vez, estos modos de "ver" conllevan cierta complejidad. El cómo se cuentan las cosas está lleno de matices, de formas diferentes de narrar y generar pensamiento, cultura contemporánea participativa. La cultura no sólo se puede explicar desde parámetros distantes; también en la proximidad. Lo social es próximo y su relación con lo que acontece resulta necesario dentro de un espacio social diferenciado: las artes.

Palabras clave: CULTURA; SOCIAL; ARTE; DIVERSIDAD; NARRAR

\section{THE DIFFERENT LOOKS TO THE NOTION OF CULTURE AND THE EFFECTS OF THE CULTURAL GLOBALIZATION}

Abstract

The concept "culture" it has evolved along several centuries, as well as his relation with the society. From his origins, in the first analyses developed by the social sciences (s.XIX), did necessary a reflection and precise interpretation of the use of this concept inside the distinct fields that generate knowledge. New codes, alternative cultures, new limits and openings enrich the artistic panorama but to his time, these ways of "see" they comport some complexity. The how explain the things is full of nuances, of different forms to narrate and generate thought, participatory contemporary culture. The culture no only can explain from distant parameters; also in the vicinity. The social is next and his relation with what becomes results necessary inside a social space differentiated: the arts.

Keywords: CULTURE; SOCIAL; ART; DIVERSITY; NARRATE

\footnotetext{
Martínez Samper, Carmen. "Las diferentes miradas a la noción de cultura y los efectos de la globalización cultural". AusArt 6 (1): 225-234. DOI: 10.1387 /ausart.19467
}

\section{AUSART}




\section{INTRODUCCIÓN}

Nuevos modos de conocimiento, de concebir la cultura y el arte, desbordan la configuración de los modos de comunicar más tradicionales y académicos. Las tres concepciones dominantes integradas por la humanista, la antropológica y las artes nos permiten organizar parcelas que se suman dentro de la riqueza de un concepto que más que ambiguo es amplio. El primero de ellos nos lleva a los albores de los siglos XVIII y XIX. Para iniciar esta reflexión en torno a la concepción humanista de cultura no debemos pasar por alto el origen de la palabra. En ella se asienta el sentido de cuanto se define, por ello, su origen latino "culturae", que proviene del verbo cultivar, es decir el cuidado del campo, ya nos aporta una visión de su categoría. La cultura, por tanto, es un "acto". Mientras en el XIII se centraba en la parcela de tierra cultivada por ello, la cultura se relacionaba con un estado (de la tierra cultivada), en los s. XVI y XVII la cultura es lo cultivado que nace del acto o acción de cultivar. Esta primera reflexión en torno a la semántica de la propia palabra ya nos abre un abanico de posibilidades, de vías por las que indagar, y resulta especialmente interesante cómo la acción y el estado se unen para evolucionar conjuntamente en una dirección de la cultura como medio para enriquecer al individuo durante un proceso de cultivo del que surgirán una serie de conocimientos como frutos. Es, una evolución que se manifiesta en la unión del ser y el hacer.

La cultura contemporánea en su dinamismo, recoge lo anterior y aborda nuevos retos, muchos de ellos sujetos a nuevos campos de actuación donde el ámbito social se incorpora de forma reivindicativa en la sociedad y entra a formar parte destacada de este ámbito. Por ello, entre los temas que se incorporan a la acción, se generan sucesivas intervenciones sociales, ya sean o no vecinales, por medio de asociaciones que se nutren de colectivos de artistas que trabajan para dar visibilizar a la realidad de algunos barrios con problemas para mantener su identidad y evitar que se potencien intereses ajenos a la población de estas zonas, en muchos casos considerados marginales. La actividad cultura también está ahí, en lo sencillo y en el día a día. A través de sus agentes, de las asociaciones, de las manifestaciones acompañadas de actividades vinculadas a la vida que todos conocen y comparten como una forma de vivir manteniendo su identidad. Los entornos se activan y surge la implicación vecinal con la cultura para mejorar entornos y crear puntos de encuentro mejorados.

El conjunto de saberes se transmiten y se comparten. Es una forma de comunicación que engloba desde lo más complejo a lo más sencillo, dentro de una 
sociedad que evoluciona y articula desde un oficio artesanal, una narración oral y unos gestos, a una reproducción con tecnología 3D, a un sonido digitalizado o a una imagen en movimiento que surge dentro de una pantalla plana de alta resolución.

Nos recuerda Gastón Bachelard en la introducción para su obra "Intuición del instante" ([1932] 2002, 7):

Cuando un alma sensible y culta recuerda sus esfuerzos por trazar, según su propio destino intelectual, las grandes líneas de la Razón, cuando estudia, por medio de la memoria, la historia de su propia cultura, se da cuenta de que en la base de sus certidumbres íntimas queda aún el recuerdo de una ignorancia esencial. En el reino del conocimiento mismo hay así una falta original, la de tener un origen; la de perderse la gloria de ser intemporal; la de no despertar siendo uno mismo para permanecer como uno mismo, sino esperar del mundo oscuro la lección de la luz. ${ }^{1}$

\section{CULTIVAR AL INDIVIDUO Y JERARQUIZAR POR GRUPOS}

A partir de la evolución con la que se concibe el concepto de cultura surgirá una diferencia entre lo que está "cultivado" y lo que no lo está y cómo se puede pasar de uno a otro estado simplemente por la acción. Se inicia una sectorización de la misma que en el siglo XVIII deriva hacia las ciencias, las artes y las letras.

En el siglo XVII la cultura ya se centra en el individuo que tiene cultura, que es civilizado, que ha recibido instrucción y la mente será el terreno propio para el cultivo, cuyo carácter redunda en el universalismo de un concepto que progresa y se racionaliza dando lugar a la suma de los saberes. Estos saberes que se acumularán y transmitirán de forma independiente, a través de la historia de los pueblos, conlleva un uso más extendido de la palabra civilización, donde todos estos aspectos confluyen para dar entidad a un estado universal de la humanidad (el movimiento Iluminista y la Razón, así lo acogen) sacando de la irracionalidad y de la ignorancia al ser humano. Este modelo, potenciado por la burguesía naciente, hace que la universalidad derive hacia una jerarquización entre diferentes grupos que nos llevan a otras realidades observables: 
La Kultur (cultura en alemán) englobará un desplazamiento de lo social a lo nacional junto a una noción particularista que se contrapone a la idea universalista y formal de civilización, anteriormente señalada, como algo específico que revierte en un carácter nacionalista. Incluso este hecho conlleva a que una nación se sienta por encima de otra.

$$
\text { Todos NO la poseen }
$$

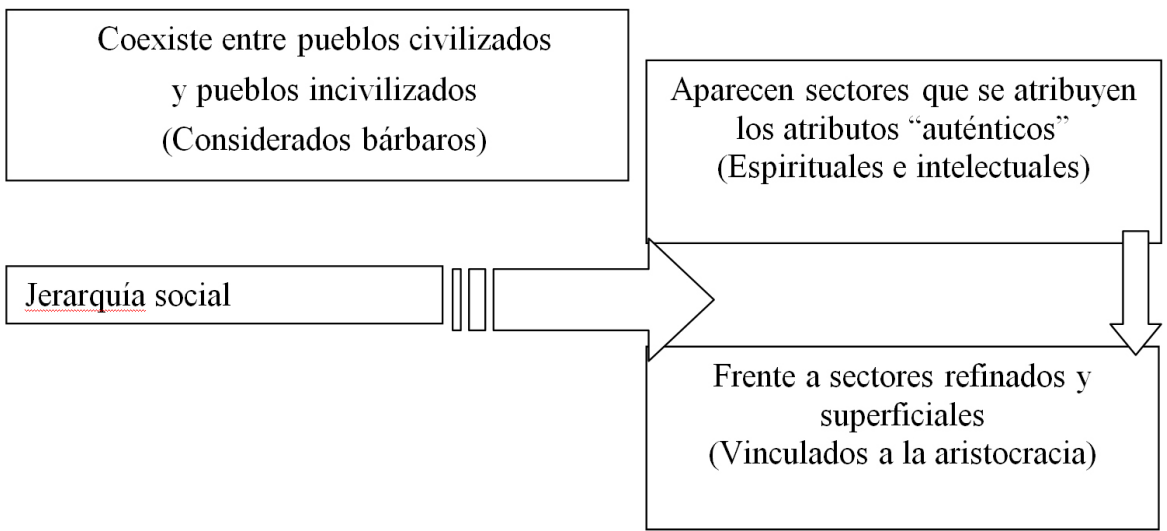

Lo que dentro de una misma nación marcaba diferencias sociales entre quienes tenían cultura y quienes no la poseían, aquí adquiere una globalidad cuando atiende a la cultura como un concepto que se refiere a un carácter definitorio de una nación frente a las otras.

Todas la diferencias que van surgiendo tienen su coordinador en el sector educativo (que permite acceder a otro estatus) donde las actividades específicas de unos cuantos (la intelectualidad) y las distancias que marcaban esta especificidad, requería de unos mecanismos donde la situación revirtiese por medio de su entendimiento, que en el modelo anglosajón se agrupaba entre las élites, quienes reunían los valores espirituales y encarnaban los valores de la vida utilitaria y material; siendo estos últimos considerados de manera restrictiva, jerarquizada y crítica. 


\section{OTRAS APORTACIONES}

Al llegar a los aportes de la sociología en la dimensión semiótica-antropológica de cultura, la definición de "habitus" como concepto mediador entre el espacio social y el espacio simbólico nos llevan a la relación que esta forma de percibir el espacio tiene como "un orden y una experiencia" que en arte adquiere cierta trascendencia.

No existe enunciado artístico que no refleje la actitud del hombre hacia el espacio. Todo enunciado artístico es una proyección directa, aunque inconsciente, del impacto del mundo sobre el hombre: de otro modo, no podría haber sido concebido. Lo mismo en sus acciones que en su arte, el hombre revela su respuesta a su entorno. Toda acción - por banal o primitiva que sea- brota de un marco de referencia filosófico. Toda obra de arte es un registro psíquico. La actitud del hombre hacia el espacio es el reflejo psíquico de su mundo visual.

(Giedion [1981] 2003, 30)

La actitud es cultural y se aprende dentro de un espacio definido en el que nacemos, nos desarrollamos... desde lo local a lo global. La cultura no sólo se puede explicar desde parámetros distantes sino que también en la proximidad tiene su focalización. Lo social es próximo y su relación con lo que acontece es cultural entre el hombre y sus semejantes; el hombre o individuo y las cosas entre las que dota de protagonismo al cuestionarse el porqué de las mismas. $Y$ es así como la cultura se puede definir dentro de un espacio social diferenciado (cultura de las artes). Este espacio para la creación es específico y engloba a la producción, la creación y la valoración de bienes culturales. Estos últimos se enmarcan en un contexto y son reconocidos como tales por pertenecer a una época y articularse dentro de una sociedad concreta que los define. En este sentido, y a partir de la historiografía, nos enfrentamos a las diferentes vertientes que enmarcan los aspectos que estructuran su estudio. De nuevo, como ya hemos señalado al definir el concepto de cultura, las variables a la hora de establecer una clasificación abren un nuevo abanico de posibilidades diversas. Desde la ordenación cronológica, la agrupación por estilos, el estudio de las obras partiendo de la biografía de los autores, las técnicas, etc. Por todo ello, el historiador social de arte Arnold Hauser señala que las producciones artísticas son un reflejo de la estructura económico-social de una época y Ernst Gombrich pone en cuestión esta vía de análisis a partir de una "lógica de situaciones", con un enfoque más específico en el que articula 
arte y sociedad en un microcosmos formado por la relación entre artistas y clientes, mecenazgo y lugares de exhibición.

Las transformaciones que se dan en la esfera del arte como integrante de la cultura, y en la que los aspectos cultos y populares adquieren mayor o menos importancia, hasta llegar a desaparecer ese estilo tan historiográfico de limitar las distintas posibilidades de hibridación, que ya con las vanguardias del siglo XX comienzan a diluirse; de lo particular se da un salto a lo global, y más concretamente a la proyección global, rompiendo con los localismos. Esta relación entre la cultura y lo social determina su vinculación con lo político. En esta estructuración se acarrea el aspecto económico porque todo lo vinculado al arte genera inversión y beneficio aunque se inscriba en falacias altruistas que nada tienen que ver en una profesionalización del hecho artístico.

Desde el arte se incide en la actualidad, en los debates, en la generación de reivindicaciones $\mathrm{y}$, el protagonismo que fomenta un sector artístico determinado, reivindicativo, es una función social que impacta sobre el ciudadano y la sociedad que lo acoge, que lo niega incluso y que "decapita" una forma de comunicar y educar como sucede actualmente con las enseñanzas artísticas (consideradas un modo de distracción para los estudiantes, según declaraciones del ministro español de Cultura en $2013^{1}$ ), en vez de reconocer su valor para avanzar en una sociedad donde la creatividad siempre tuvo un lugar y donde una parte de nuestra economía se mueve por sectores, algunos de ellos vinculados al patrimonio (generalmente artístico) y al diseño y que, por ello, debiera incidir cada vez más, en el libre pensamiento y la identidad dentro de la globalización cultural en la que estamos inmersos y que no debiera quedar desatendida.

\section{GLOBALIZACIÓN}

La globalización a la que se dirige este fenómeno económico y socio-político conlleva una manera de contar las cosas que irrumpe en nuestra vida aportando una serie de transformaciones que conforman nuevos imaginarios y construyen identidades con unos rasgos renovados. El nuevo "mundo" se identifica con la pérdida de la individualidad al transformar un ente en colectivo. Lo privado es parte de una cultura universal que en la globalización puede homogeneizar y estandarizar lo particular asumiendo los riesgos que conlleva 
la pérdida de la diversidad cultural y sus manifestaciones locales. Por otra parte, permite eliminar barreras y prejuicios pero la línea que separa estas dos posturas es tan fina y delicada como peligrosa, sobre todo en el mantenimiento de la cultura propia. Actualmente los límites geográficos ya no son las fronteras territoriales puesto que en la era de la información y de la globalización económica, las naciones como tales pasan a un segundo plano, siendo sustituidas por "el mercado mundial". Pero esta visión que parece catastrofista en realidad nos conduce a la construcción de una cultura enriquecida por la diversidad y en ella todas las aportaciones son nutrientes necesarios para crear esta nueva realidad del siglo XXI, a la que podemos restar la importancia que tiene. Se generan los no-lugares, la homogeneización de espacios de tránsito común para el comercio y el viaje (franquicias y aeropuertos) donde el imperialismo de lo telemático con sus pros y contras se impone. Todo se ha producido en un periodo de tiempo breve.

La globalización o mundialización obliga a pensar en los procesos culturales atendiendo a esta manera de pensar; de ser. Nuevos espacios culturales y redes sociales generan los procesos de construcción de la identidad territorial que busca su reconocimiento dentro de la diversidad de la que forman parte. Un mundo plural que sea articula con puntos de vista múltiples pero que tienen patrones cuya finalidad está dirigida a guiar un estilo de vida, alejado en la mayoría de los casos, de un hecho cultural propio pero que se va instalando a través de los mass media, de las redes sociales, de los informativos tendenciosos. Estamos importando y asimilando la cultura norteamericana y dejando de lado las aportaciones de nuestra propia cultura, la que marca el porqué de nuestras cosas y nos sitúa en una realidad contextualizada. Con ello, percibimos que nada es inalterable, estático o inmutable. El concepto evoluciona como cualquier proceso iniciado. Ni todo es bueno, ni todo es malo. Renace una realidad sobre la que debemos reflexionar de forma crítica. Prevalece la multiculturalidad porque el mundo se abre, comparte y su coherencia depende del buen hacer de todos. Pensar en la identidad de un territorio tiene sus riesgos si este pensamiento nos conduce al extremismo.

De un extremo a otro, el aislamiento y la desconexión no conducen a ninguna parte y precisan asumir la realidad conectada entre culturas diferente. Lo que sería cuestionable es si esta es la globalización necesaria, si hay otros modos de proceder y si la economía y la sociedad global siguen un esquema dado que tal vez será reinventado y reconstruido. En él, tal vez será necesario dejar un espacio para aquellas culturas que quieren vivir aisladas y donde la intromisión no se procesa como algo natural sino que se sigue con el ideario 
colonialista que, lo que pretende es invadir un territorio propio que queremos sumar al nuestro, sin preguntar si es lo que desean.

\section{A MODO DE CONCLUSIÓN}

Desde los aspectos económicos, la cultura forma parte de la producción de bienes y servicios. La ciudad es un nexo donde confluyen intervenciones sociales de distintos ámbitos, entre ellos el artístico. A lo largo del artículo que nos ocupa encontramos de nuevo las palabras como vínculo necesario para definir procesos. Hablamos de "consumo, factor expresivo, identidades sociales, estilos de vida, estética de la producción, diseño, espacio urbano, márketing, publicidad, vida cotidiana, barrios artísticos, simbología..." (Rius \& Zarlanga 2010, 19).

En torno a la globalización cultural, con las nuevas tecnologías las distancias se han desvirtuado hacia otra realidad que es "la distancia cero", es decir, que de una forma simultánea ponemos en comunicación puntos que físicamente están alejados y que gracias a las redes, a la comunicación que nos une por medio de internet, hacen que las fronteras y el tiempo modifiquen su estructura.

Una nueva forma de conocer y de compartir conocimiento e información nos llevará a ámbitos que se conciben con una globalidad que se inmiscuye en nuestra cotidianeidad acortando distancias y generando un nuevo lenguaje en el que lo global se torna universal. Los debates que se originan a partir de los numerosos avances, estudios y posicionamientos hacia la realidad cultural que nos envuelve, nos encamina hacia una globalización que sólo la particularidad de algunos factores propios de un país quedan protegidos como algo identitario gracias al idioma y las costumbres más arraigadas. Pero todo es influenciable por lo que cualquier cuestionamiento que pueda surgir debe analizarse desde una perspectiva más amplia, evolucionada, diferente y cada vez más compleja. $Y$ es, en este sentido, donde nacen las interrogantes sobre los límites. Ya se marcaban con anterioridad al considerar que la cultura no sólo es industria cultural, es decir, una forma de concebirla desde un punto de vista vinculado a lo económico sino que es parte de la política, dirigida a una comunidad como medio para transformar la sociedad. Es ahí donde adquieren un papel destacado las artes en cuanto al enriquecimiento espiritual por 
lo que ya no sólo existe una protección sino que se alimenta una promoción de la creación. Pero, ese tipo de apoyos que se brindan a estas actividades de promoción del arte y los artistas deben venir avaladas por un criterio que no conlleve implícito un elitismo incomprensible de las inversiones realizadas. Aunque sea necesaria la difusión de la alta cultura y el apoyo a las manifestaciones minoritarias, la necesidad de unos criterios bien estructurados donde el ciudadano pase de ser un ente pasivo a un ciudadano participativo y protagonista dentro de la promoción de la ciudad creativa, donde la regeneración de espacios olvidados, desatendidos, "vacíos", son un punto de eclosión para activar procesos culturales donde la ciudad es el escenario y los ciudadanos sus actores activos.

\section{Referencias}

Bachelard, Gastón. (1932) 2002. La intuición del instante. Traducción de Jorge Ferreiro. México DF: Fondo de Cultura Económica

- . (1957) 2000. La poética del espacio. Traducción de Ernestina de Champourcin. México DF: Fondo de Cultura Económica

Bauman, Zygmunt. (1999) 2003. Modernidad líquida. Traducción Mirta Rosenberg \& Jaime Arrambide Squirru. México DF: Fondo de Cultura Económica

Becker, Howard. Saul. (1982) 2008. Los mundos del arte: Sociología del trabajo artístico. Traducción, Joaquín Ibarburu. Buenos Aires: Universidad Nacional de Quilmes

Cuche, Denis. 1999. La noción de cultura en las ciencias sociales. Traducción de Paula Mahler Buenos Aires: Nueva Visión

Giedion, Sigfrido. (1981) 2003. El presente eterno: Los comienzos del arte. Versión española de María Luisa Balseiro. Madrid: Alianza

Gombrich, Ernest Hans. (1963) 1998. Meditaciones sobre un caballo de juguete y otros ensayos sobre la teoría del arte. Versión castellana de José María Valverde. Madrid: Debate

Gubern Garriga-Nogués, Román. 1996. Del bisonte a la realidad virtual: La escena y el laberinto. Barcelona: Anagrama

Hall, Edward Thomas. (1972) 2003. La dimensión oculta. Traducción de Félix Blanco. Buenos Aires: Siglo XXI

Hauser, Arnold. 1969. Historia social de la literatura y del arte. Trads., A. Tovar \& F.P. Varas-Reyes. Madrid: Guadarrama

López Rodríguez, Silvia. 2003. "El túnel de las metáforas: Percepción de la vivienda y del entorno urbano como experiencia artística". Scripta Nova 7. http://revistes.ub.edu/index. php/ScriptaNova/article/view/674

Molinuevo Martínez de Bujo, José Luis. 2004. Humanismo y nuevas tecnologías. Madrid: Alianza 
Rius Ulldemolins, Joaquín \& Matias I. Zarlenga. 2010. "La cultura en la sociedad contemporánea: Conceptos, transformaciones y nuevas tendencias". Barcelona: UOC-UdG-UIB

Selma de la Hoz, Juan Vicente. 1996. Imágenes de naufragio: Nostalgia y mutaciones de lo sublime romántico. València: Direcció General de Promoció Cultural, Museus i Belles Arts

Simmel, Georges. (1903) 1984. "Puente y puerta". En El individuo y la libertad: ensayos de crítica de la cultura. Traducción y prólogo de Salvador Más. Barcelona: Península

Tatarkiewick, Wladyslaw. (1975) 1996. Historia de las seis ideas: Arte, belleza, forma, creatividad, mímesis, experiencia estética. Traducción de Francisco Rodríguez Martín. Madrid: Tecnos

\section{Notas}

1 El ministro Wert llegó a hablar de asignaturas que "distraen". Ver: "Artes y filosofía pasan a segundo plano". Por J. A. Aunión. (El País, 28 de noviembre de 2013). 